\title{
Appraisal of Schoolchildren's Feelings and Attitudes towards Dentists and Their Potential Impact on Oral Health
}

\author{
Chirine A Malak ${ }^{1}$, Carole Chakar ${ }^{2}$, Alain Romanos ${ }^{3}$, Samar Rachidi ${ }^{4}$
}

\begin{abstract}
Aim: To assess schoolchildren's feelings and attitudes towards dentists and their potential impact on oral health.

Materials and methods: 7902 schoolchildren (12 and 15 years old) attending public and private schools completed a questionnaire that assessed their feeling and attitude toward dentists. DMFT and CPI indices were used to assess dental caries and periodontal diseases respectively according to the World Health Organization method and criteria.

Results: $79.7 \%$ of all schoolchildren who participated in this study had been to the dentist. $24.7 \%$ reported that they are afraid of dental visits, pain being the main reason for this disturbing feeling $(88,2 \%)$. Of the children, $81.4 \%$ preferred a female dentist; $82.3 \%$ preferred a dentist with a colored coat and $80.3 \%$ favored a renovated dental facility. $91.1 \%$ of the children are irritated by the noises in the dental clinic. The mean DMFT and CPI scores were significantly higher in patients with dental fear, and in patients who never had a dental visit.

Conclusion: Meeting patient's perceptions and preferences regarding their dentist may help to reduce the potential dental anxiety and thus ensure the delivery of a high-quality dental treatment leading to better oral health status.

Clinical relevance: Patient perception about dentists is affected by a series of factors related to the dentist, the patient, and the dental clinic. Patients who experience the worst perceptions of dental professional tend not to seek dental care, which leads to a bad oral health status, hence the importance of further studies in this area to improve such perceptions, and promote attitudinal changes toward positive health-seeking behavior. Keywords: CPI, Dental anxiety, Dental fear, Dentist perception, DMFT, Lebanon, Oral health status.

The Journal of Contemporary Dental Practice (2021): 10.5005/jp-journals-10024-3018
\end{abstract}

\section{INTRODUCTION}

The dentist-patient relationship has been and remains a keystone of care; it has received philosophical, sociological, and literary attention since Hippocrates, and remain the subject of many studies and researches. In dental practice, most children are uncooperative and sometimes very difficult to manage. This behavior derives from the treatment carried out and from the sentimental state of the children.

Dental fear or anxiety is considered a global public health concern and a fundamental cause of major behavioral issues leading to a complete rejection of dental treatment. According to Al-Sarheed, 5 to $6 \%$ of the population and $16 \%$ of schoolchildren experience anxiety during dental visits. ${ }^{1}$ Miller highlighted the importance of reducing patient's anxiety and fear of dentistry as much as possible since this behavior is significantly correlated with oral health issues. ${ }^{2}$ In comparison with caries-free children, Lahti et al. highlighted a higher level of dental fear among caries-active children due to previous traumatic dental experiences. ${ }^{3}$ Boys with a decayed, missing, and filled teeth (DMFT) score $\geq 1$ suffer from significantly higher mean dental anxiety than those who were free of caries. ${ }^{4}$

The power of good dentist-patient relation has its impact on dental health: the patient fear is decreased leading to effective dental therapy. Children who reported a friendly relation with their dentist encounter less dental fear and tend to have regular dental visits and thus better oral status. ${ }^{1}$

The vision of children and adolescents toward their dentists and dental treatment has not been previously investigated in
${ }^{1}$ Clinical and Epidemiological Research Laboratory, Doctoral School of Science and Technology, AZM Center for Biotechnology, Tripoli, Lebanon

${ }^{2}$ Department of Periodontology, Faculty of Dental Medicine, St Joseph University of Beirut, Beirut, Lebanon

${ }^{3}$ Department of Periodontology and Implantology, Faculty of Dentistry, Lebanese University, Beirut, Lebanon

${ }^{4}$ Clinical and Epidemiological Research Laboratory, Faculty of Pharmacy, Lebanese University, Hadath, Lebanon

Corresponding Author: Chirine A Malak, Clinical and Epidemiological Research Laboratory, Doctoral School of Science and Technology, AZM Center for Biotechnology, Tripoli, Lebanon, Phone: +0096170960911, e-mail: chirineabdelmalak@hotmail.com

How to cite this article: Malak CA, Chakar C, Romanos A, et al. Appraisal of Schoolchildren's Feelings and Attitudes towards Dentists and Their Potential Impact on Oral Health. J Contemp Dent Pract 2021;22(1):23-26. Source of support: Nil

Conflict of interest: None

Lebanon. Indeed, a robust science of the dentist-patient encounter and relationship in schoolchildren can guide decision-making in health care plans and thus prevent later oral health problems since dentist image begins to elaborate during childhood and once it is established, it remains forever. ${ }^{5}$

In this perspective, the main objective of this current study is to assess schoolchildren's feelings and attitudes toward dentists and their potential impact on oral health.

() Jaypee Brothers Medical Publishers. 2021 Open Access This article is distributed under the terms of the Creative Commons Attribution 4.0 International License (https://creativecommons.org/licenses/by-nc/4.0/), which permits unrestricted use, distribution, and non-commercial reproduction in any medium, provided you give appropriate credit to the original author(s) and the source, provide a link to the Creative Commons license, and indicate if changes were made. The Creative Commons Public Domain Dedication waiver (http://creativecommons.org/publicdomain/zero/1.0/) applies to the data made available in this article, unless otherwise stated. 


\section{Methods}

The current study is a nationwide cross-sectional survey carried out in the six governorates of Lebanon from September 2018 to June 2019; it is a part of a PhD program that aims to assess the oral health status of Lebanese schoolchildren. A sample of 7902 children attending secondary public and private schools in urban, peri-urban, and rural areas of Lebanon was investigated. This study was approved by the ethics committee of the Azm Center for Research in Biotechnology and Its Applications, Lebanese University (document no. CE-EDST-1-2021) and, informed consent forms in the Arabic language were submitted to the school management, head teacher, and parents before participation.

The sampling of the study population and the data collection methods used are detailed in a previous publication. ${ }^{6}$ In brief, in the first stage, a multistage stratified cluster sampling was performed according to the World Health Organization (WHO) guidelines, ${ }^{7}$ considering the six governorates of Lebanon as strata: Beirut, South of Lebanon, North of Lebanon, Nabatiyeh, Bekaa, and Mount Lebanon. In the second stage, the schools were chosen at cluster level with probability proportional to size sampling method; selection of participants in the private and public sector was performed. In the third stage, classes from the selected schools were chosen. Non-Lebanese children and children with special needs were exclusion criteria. Based on the lists provided by the Lebanese ministry of education regarding the number of 12 and 15 years old registered schoolchildren and following WHO guidelines in sample calculation, 3985 children aged 12 years and 3917 aged 15 years were included in the study.

The questionnaire evaluated children's perceptions of their dentists. Previous dental visits, attitude toward dentists, preferences regarding dentist's gender, outfit, safety equipment, and the design of the clinic were the studied variables. The validity and reliability of the questions were tested in a previous pilot study. The questionnaires were formulated in English then translated and administrated in the Arabic language.

Seven calibrated dental examiners used the WHO criteria (2013) to assess the oral status of the investigated sample. ${ }^{7}$ DMFT and Community Periodontal Index (CPI) indices were used to record dental caries and periodontal diseases; the intra-examiner variability was satisfactory (kappa value $=0.82$ ). The questionnaire data and clinical data were merged for statistical analysis.

$\mathrm{The} \mathrm{IBM}^{\circledast} \mathrm{SPSS}^{\circledast}$ statistics 24.0 was used to perform the statistical analyses. The alpha error was set at 0.05. Chi-square test, MannWhitney test, and Student's test were used to generate descriptive and analytic statistics and thus evaluate the relationship between the variables. Parameters normally distributed were tested by Spearman's rho correlation.

\section{Results}

A total of 7902 children (3806 males and 4096 females) were included in this study. The examined sample was almost equally distributed between 12-year-old (50.4\%) and 15-year-old (49.6\%) children. $56.1 \%$ and $43.9 \%$ of the participants were recruited from private and public schools, respectively. The vast majority were living in a suburban area (63.0\%). Consistently with the sampling strategy, the majority of the respondents were from Mount Lebanon (35.5\%) and North of Lebanon (23.6\%) whereas the minorities of the surveyed sample were from Nabatiyeh (7.5\%) and Beirut (8.0\%). Almost $1 \%$ of the participants suffered from at least one chronic disease (such as asthma, diabetes, epilepsy, hearing trouble,
Table 1: The response of the children to whether they are afraid of the dental visits according to the school type, gender, and location

\begin{tabular}{lccc}
\hline & Yes (\%) & No (\%) & Significance \\
\hline $\begin{array}{l}\text { School type } \\
\text { Private }\end{array}$ & 24.36 & 75.64 & Ns \\
Public & 25.14 & 74.86 & \\
Gender & & & $* * *$ \\
Female & 28.61 & 71.39 & \\
Male & 20.49 & 79.51 & $* * *$ \\
Location & & & \\
Urban & 39.94 & 60.06 & \\
Peri-urban & 18.35 & 81.65 & \\
Rural & 44.91 & 55.09 & \\
\hline
\end{tabular}

*** $p<0.001$

hemophilia, and hypertension). The majority of participants were nonsmokers (84.2\%).

Our previous results showed that only $3.4 \%$ of participants have a healthy periodontal condition (CPI score 0 ). On the other hand, $44.0 \%$ of participants showed gingival bleeding (CPI score 1 ), $50.5 \%$ exhibited calculus with bleeding (CPI score 2 ) whereas only $2 \%$ were characterized by shallow pockets $(4-5 \mathrm{~mm}$; CPI score $3)$. Among the 12-years-old children, the prevalence of caries was $88.6 \%$ and the mean DMFT per child was $4.90 \pm 3.484$. The prevalence of caries among 15 -years-old children was $90.5 \%$ and the mean DMFT was $2.5 .^{6}$

$79.7 \%$ of all the schoolchildren who participated in this study had been to the dentist. And $24.7 \%$ reported that they are afraid of dental visits; of these, $88.2 \%$ reported pain as the main reason behind this disturbing feeling. Dental fear was higher among younger children $(p<0.01$ ). $87.6 \%$ of children stated that they trust their dentist and $96.4 \%$ reported that their dentist does not explain/ explain sometimes the dental procedure during the treatment.

Table 1 summarizes the response of the children to whether they are afraid of the dental visits according to the school type, gender, and location. A statistically significant correlation between the fear of visiting dentists, gender, and the location is proved: females and children living in rural areas are more afraid of dental visits.

The children's vision of their dentists and dental clinic are presented in Table 2. A total of $81.4 \%$ of the children favored to be treated by a female dentist. A dentist wearing a mask and a colorful outfit was chosen respectively by $73.5 \%$ and $82.3 \%$ of the participants. While $18 \%$ of them preferred their dentist not to wear safety equipment, $4.7 \%$ stated that they prefer a dentist with protective glasses and $3.8 \%$ chose a dentist with both protective gears. $80.3 \%$ of the children preferred to be treated in a decorated dental facility.

Children stated multiple reasons for discomfort in relation to dental visits (Table 3). $91.1 \%$ of the children are irritated by the noises in the dental clinic. There is a statistically significant correlation between the reasons for discomfort during dentist appointments and the type of school attended.

The distributions of the CPI and DMFT scores by dental visits and fear of dentists are shown in Table 4. Children suffering from dental fear present significantly higher mean DMFT and CPI scores than those without dental fear. Besides, children who had a previous dental visit have significantly lower CPI and DMFT scores than those who never visited a dentist. 
Table 2: Children's perceptions of their dentists and dental clinic

\begin{tabular}{lc}
\hline Response & Percentage (\%) \\
\hline Young dentist & 82 \\
Old dentist & 18 \\
Male dentist & 18.6 \\
Female dentist & 81.4 \\
Colored coat & 82.3 \\
White coat & 17.7 \\
No dental protection & 18 \\
Protective glasses & 4.7 \\
Mask & 73.5 \\
Mask and protective glasses & 3.8 \\
Decorated clinic & 80.3 \\
Undecorated clinic & 19.7 \\
\hline
\end{tabular}

Table 3: Sources of discomfort in a dental clinic according to gender and school type

\begin{tabular}{lcccc}
\hline & \multicolumn{2}{c}{ Gender } & \multicolumn{2}{c}{ School type $(P<0.01)$} \\
\cline { 2 - 5 } & $F(\%)$ & $M(\%)$ & Private (\%) & Public (\%) \\
\hline Annoying & 0.05 & 0.08 & 0.05 & 0.09 \\
Odors & 1.05 & 0.71 & 1.24 & 0.43 \\
Position & 0.24 & 0.34 & 0.36 & 0.2 \\
It takes time & 0.39 & 0.42 & 0.54 & 0.23 \\
Instruments & 1.05 & 0.6 & 1.2 & 0.37 \\
Noises & 93.63 & 93.82 & 92.24 & 95.62 \\
Open & 3.59 & 4.02 & 4.37 & 3.06 \\
mouth & & & & \\
\hline
\end{tabular}

Table 4: Distribution of CPI and DMFT scores according to dental visit and dental fear

\begin{tabular}{lll}
\hline & \multicolumn{1}{c}{$C P I$} & \multicolumn{1}{c}{$D M F T$} \\
\cline { 2 - 3 } & Mean $\pm S D$ (median) & Mean $\pm S D$ (median) \\
\hline Dental visit & & \\
Yes & $1.8 \pm 1.31$ & $2.52 \pm 2.23$ \\
No & $2.8 \pm 2.35$ & $3.32 \pm 3.16$ \\
& $p<0.01$ & $p<0.01$ \\
Dental fear & & \\
Yes & $2.5 \pm 2.3$ & $3.56 \pm 3.2$ \\
No & $1.6 \pm 1.3$ & $2.85 \pm 3.6$ \\
& $p<0.01$ & $p<0.01$ \\
\hline
\end{tabular}

\section{Discussion}

Dental anxiety can manifest as dental avoidance, which can lead to extreme oral health complications or low quality of life. Within a dental office, anxious patients can present as irritable and/or uncooperative and tend to have a greater pain response than their calm counterparts. These responses are problematic for not only the patient but for dental professionals since these negative feelings of anxiety can translate to dental staff and clinicians and indirectly affect the quality of the dental treatment. In the present study, $24.7 \%$ of the patients reported that they are afraid of dental visits and $88.2 \%$ of those patients stated that fear of pain is the main reason that lacks behind this disturbing feeling. These results are in harmony with a previous study done in $2011 .{ }^{8}$ Given the negative impact of dental fear for all concerned, patients with dental anxiety must be managed correctly. Going to the dentist is considered the second most frequent fear in the population. ${ }^{9}$ To overcome these negative perceptions and to combat fear, dentists must build a trustworthy relation with patients, mainly children. ${ }^{1}$

The origins of dental anxiety are poorly understood, but they can be conceptualized as being either "endogenous" or "exogenous."10 $91.1 \%$ of the patients enrolled in the current study reported that noise in the dental clinic is the main cause of discomfort and is on the top of the list of the exogenous determinants of dental anxiety. These findings emphasize the necessity of noise control of various dental equipment and the potential use of audiovisual distraction methods to overcome this anxiety. However, our findings differ from the Al-Sarheed study that reported injection, tooth extraction, and dental tools as a cause of dental anxiety, highlighting the importance of the tell-show-do technique and the strict usage of necessary dental tools. ${ }^{1}$

Endogenous dental anxiety can appear as the reflection of the patient's personality or maybe a part of a general anxiety syndrome and it was not studied in the present survey.

Communication is central to the dentist-patient relationship, and attire is an influential source of nonverbal communication, especially in the absence of other information; what a doctor wears can also be "an important factor in the degree of trust and confidence" among patients. ${ }^{11}$ Many studies have shown that the white outfit as the emblem of health, purity, and cleanliness is preferred by adolescents and children. ${ }^{12,13}$ Other studies stated that the majority of patients preferred colored outfits that may give the medical professional a less formal look; ${ }^{14}$ these findings match our results: $82.3 \%$ of the patients are less attracted to white coats and prefer a dentist with a colored outfit.

In correlation with previous studies, ${ }^{15,16}$, patients in this survey preferred being treated by a female dentist. In comparison with their male colleague, female dentists are known to be more kind, emotional, and compliant. Besides, they prefer being treated in a decorated dental clinic for the positive vibes that it may generate or the distraction it causes during dental treatment. The finding is in agreement with Al-Sarheed and McCarthy et al. studies where the majority of the children favored a decorated dental clinic design with toys and posters over a routine and bare clinic. ${ }^{1,15}$

Age is a crucial factor that may affect patients' attitudes toward dentists. Regarding patient preference for different age-groups in dentists, studies have revealed that older professionals are preferred, as it is believed that they encounter higher interpersonal competency and vast experience when compared to younger professionals. In contrast, other studies suggest that patients have better perceptions of younger professionals, as they use the latest techniques and very advanced technological equipment that may generate less noise and vibrations. ${ }^{17}$ In correlation with these studies, $82 \%$ of the participants in the current survey preferred being treated by a young dentist.

The use of protective clothing is safe for both the patient and the dentist and should be a vital part of the daily practice in every dental facility. However, some patients may be intimidated by those gears and may find them a source of discomfort and anxiety. Our study showed that $18 \%$ of the investigated patients preferred a dentist with no protection and $73.5 \%$ preferred a dentist with a mask only. These findings are consistent with the results of previous studies. ${ }^{16,18}$ Explaining to the patient the importance of these devices in infection control may overcome this issue. 
In our study, $87.6 \%$ of children stated that they trust their dentist. Confidentiality, respected ethical principles, patient autonomy, and medically efficient treatment are the key to success for every trustworthy relation between dentist and patient. Most notably, the level of trust will directly influence the patient's assiduity toward dental visits. ${ }^{19}$

The dentist faculty of communication is crucial in the building of a favorable dentist-patient relation and will determine the outcome of every dental practice. $96.4 \%$ of the patients reported that their dentist does not or does not always explain the dental treatment for them. The lack of effective communicative skills is one of the barriers to the foundation of a successful dentist-patient relationship.

It has been reported that dental anxiety has a significant effect on oral health and the use of dental facilities, and is related to multiple adverse dental health attitudes and outcomes. ${ }^{16,20}$ The results of the current study match these findings, a higher DMFT and CPI scores were recorded in patients who expressed anxiety and fear toward dental visits. Dental fear may be a basic constituent in the "cycle of dental disadvantage" among individuals who suffer from it. Their aptness to avoid dental treatments worsen their oral status, in that the exceptional occasions on which dental visiting does occur are mostly to be emergency visits that require immediate solution, and are most likely nerve-racking for both patient and dentist. This is consistent with the results of our study; children who never visited a dentist encounter critical dental caries experience and worst periodontal status compared to children who previously had a dental visit. In the same context, Taani et al. reported contrasting results; no correlation between dental anxiety and DMFT scores was found. ${ }^{21}$

In our study, no correlation between the socioeconomic status and the child's perception toward the dentist was detected. This unexpected result may provide an opportunity for further inquiry. Regarding dental care, parents with low socioeconomic levels cannot afford dental treatments, thus they do not take their children to seek dental care, leading to the worsening of their oral status. Some studies suggest that as children grow up, and in the absence of any dental experience, they may become phobic patients; the image of the dentist is better conceived at a younger age. ${ }^{22}$

\section{Conclusion}

Dental anxiety is positively correlated with higher DMFT and $\mathrm{CPI}$ indices and therefore should be well managed in order to ensure a better oral health status. In this perspective, taking into consideration children's preferences regarding the dentist's look and dental clinic may be a step toward the building of a strong patient-dentist relationship and thus promoting a healthy oral lifestyle.

\section{Acknowledgment}

The authors would like to thank the Lebanese university for its continuous support and all the people who have contributed to the implementation of the survey at each geographic location.

\section{References}

1. Al-Sarheed M. Children's perception of their dentists. Eur J Dent 2011;5(2):186-190. DOI: 10.1055/s-0039-1698878.
2. Miller AA. Psychology considerations in dentistry. J Am Dent Assoc 1970;81:941-946. DOI: 10.14219/jada.archive.1970.0347.

3. Lahti $\mathrm{S}$, Tuutti $\mathrm{H}$, Honkala E. The relationship of parental dental anxiety and child's caries status. ASDC J Dent Child 1989;56(3):191-195. DOI: 10.1111/j.1601-5037.2005.00127.x.

4. Alvesalo I, Murtomaa $\mathrm{H}$, Milgrom $\mathrm{P}$, et al. The dental fear survey schedule: a study with Finnish children. Int J Paediatr Dent 1993;3(4):193-198. doi: 10.1111/j.1365-263x.1993.tb00083.x.

5. Pinho C, Dias H, Carvalho A, et al. Representação social da Odontologia: a contribuição da produção cinematográfica para perpetuação de um estereótipo negativo. Rev Odontol UNESP 2008;37(3):275-281 .

6. Abdel Malak C, Chakar C, Romanos A, et al. Oral health status of 12- and 15-years old Lebanese schoolchildren. EMJH 2021. Article accepted but not published yet.

7. World Health Organization. Oral health surveys: basic methods, 5th ed. Geneva: World Health Organization, 2013.

8. Diercke K, Ollinger I, Bermejo L, et al. Dental fear in children and adolescents: a comparison of forms of anxiety management practiced by general and pediatric dentists. In J Paediatr Dent 2011;22:60-67. DOI: 10.1111/j.1365-263X.2011.01158.x

9. Henríquez-Tejo, Belén R, Cartes-Velásquez, et al. Patients' perceptions about dentists A literature review. Odontoestomatología 2016;16: $36-42$.

10. Locker D, Liddell AM. Clinical correlates of dental anxiety among older adults. Commun Dent Oral Epidemiol 1992;20:372-375. DOI: 10.1111/j.1600-0528.1992.tb00702.x.

11. Chung $\mathrm{H}$, Lee H, Chang DS, et al. Doctor's attire influences perceived empathy in the patient-doctor relationship. Patient Educ Couns 2012;89(3):387-391. DOI: 10.1016/j.pec.2012.02.017.

12. Bahammam S. Children's preferences toward dentist attire in $\mathrm{Al}$ Madinah AI Munawarah. Patient Prefer Adherence 2019;13:601-607. DOI: 10.2147/PPA.S196373.

13. Petrilli CM, Saint S, Jennings JJ, et al. Understanding patient preference for physician attire: a cross-sectional observational study of 10 academic medical centres in the USA. BMJ Open 2018;8(5):e021239. DOI: 10.1136/bmjopen-2017-021239.

14. Gooden BR, Smith MS, Tattersall JN, et al. Hospitalised patients' view on doctors and white coats. Med J Aust 2001;175:219-221. DOI: 10.5694/j.1326-5377.2001.tb143103.x.

15. McCarthy JJ, McCarthy MC, Eilert RE. Children's and parents' visual perception of physicians. Clin Pediatr (Phila) 1999;38:145-152. DOI: 10.1177/000992289903800304.

16. Münevveroğlu AP, Akgöl BB, Erol T. Assessment of the feelings and attitudes of children towards their dentist and their association with oral health. ISRN Dent 2014;2014:867234. DOI: $10.1155 / 2014 / 867234$.

17. Swami V, McClelland A, Bedi R, et al. The influence of practitioner nationality, experience, and sex in shaping patient preferences for dentists. Inter Dent J 2011;61:193-198. DOI: 10.1111/j.1875595X.2011.00056.x.

18. Shulmam ER, Brehm WT. Dental clinical attire and infection-control procedures: patients' attitudes. J Am Dent Assoc 2001;132(4):508-516. DOI: 10.14219/jada.archive.2001.0214.

19. O'Malley AS, et al. The role of trust in use of preventive services among low-income African-American women. Prev Med 2004;38:777-785. DOI: 10.1016/j.ypmed.2004.01.018.

20. Dental statistics and research series Number 25 Public perceptions of dentistry: stimulus or barrier to better oral health. AlHW Dental Statistics and Research, 2002.

21. Taani DQ, El-Qaderi SS, Abu Alhaija ES. Dental anxiety in children and its relationship to dental caries and gingival condition. Int J Dent Hyg 2005;3(2):83-87. DOI: 10.1111/j.1601-5037.2005.00127.x.

22. Glazman J. Dental anxiety: personal and media influences on the perception of dentistry. [Thesis]. Pace University; 2014. 